\title{
Hypoxia and human placental development
}

\author{
John D. Aplin
}

School of Medicine and School of Biological Sciences, University of Manchester; Research Floor, St. Mary's Hospital, Manchester M13 0JH, United Kingdom. Phone: 44-161-276-6487;

Fax: 44-161-276-6134; E-mail: john.aplin@man.ac.uk.

Human developmental biology has been stirred by the emergence of evidence that the early placental environment is hypoxic (1). Plugs of cytotrophoblasts block maternal spiral arteries that supply the placental site (2), and when the intervillous space is observed through a hysteroscope, it appears devoid of maternal erythrocytes. At about the 11th week of gestation, however, the plugs are displaced and blood flow begins. As a result, the local partial pressure of oxygen increases from about 18 to 60 mm (3), whereupon the placenta develops enhanced mechanisms for protection against oxidative damage (4). Pathways of regulation of trophoblast function by oxygen are not well known, but in this issue of the $J C I$, Caniggia and colleagues (5) investigate a transcription factor that appears to participate in physiological changes during this transition. This transcription factor, hypoxiainducible factor $1 \alpha$ (HIF $-1 \alpha$ ), belongs to the basic helix-loop-helix family and functions as a heterodimer with its constitutively expressed partner HIF-1 $\beta$, or ARNT, to bind gene regulatory regions. As Caniggia et al. now show, HIF- $1 \alpha$ is present in the placenta before 10 weeks, but not at 11-14 weeks of gestation.

Most placental villi float freely in the intervillous space, but specialized anchoring villi at the periphery attach the placenta to the decidual surface (6). These anchoring villi also act as feeder sites for the many migratory extravillous cytotrophoblasts (EVT) that infiltrate the decidual interstitium and spiral arteries $(6,7)$. These cells transform the arterial walls, allowing expansion, so that the blood supply can increase with fetal demands. Transformation proceeds from very early stages until about the 18th week, suggesting that trophoblast must be recruited into this lineage in both the first and second trimester. Similarly, to sustain placental growth, differentiation along another major pathway, from stem cytotrophoblast into villous syncytiotrophoblast, must occur efficiently both before and after the oxygen transition.

The mechanism of anchoring villus formation has been illuminated by several groups using placental explants cultured ex vivo under varying concentrations of oxygen. First trimester villi, explanted onto a 3-dimensional extracellular matrix in $20 \%$ oxygen, form new sites spontaneously at their tips (8-10), whereas explants cultured in 2 or $3 \%$ oxygen show increased EVT production $(5,10,11)$. Cytotrophoblast proliferation has long been known to be higher in hypoxia $(12,13)$, although the placental oxygen sensor still remains to be identified. Furthermore, as predicted from observations in vivo, HIF- $1 \alpha$ mRNA levels are several-fold higher after culture in low oxygen. Now, following up on their earlier finding that TGF- $\beta 3$ mRNA levels decline after the oxygen transition (14), the Caniggia group shows that TGF- $\beta 3$ levels decline when HIF- $1 \alpha$ mRNA is reduced by antisense treatment. Because reduction of TGF- $\beta 3$ has no effect on HIF- $1 \alpha$ levels (5), they conclude that TGF- $\beta 3$ lies downstream of HIF- $1 \alpha$.

Beyond its effects on TGF- $\beta 3$, HIF$1 \alpha$ inhibits the expression of integrin $\alpha 1 \beta 1$ and MMP9, which are required for migration $(5,11)$. Caniggia and colleagues argue that TGF- $\beta 3$ acts in an autocrine fashion to regulate these events. Certainly, TGF- $\beta$ inhibits trophoblast migration in culture (15), but for several reasons interpretation of the new data is not straightforward. First, cytotrophoblast proliferation, migration, and colonization of decidua occur in vivo both before and after the oxygen transition $(7,16)$. Second, de novo column formation occurs in cultures in $20 \%$ oxygen (9, 10). Third, TGF- $\beta$ is abundantly expressed in decidua (17), the very environment through which trophoblast migration occurs. Thus, observations made both in vivo and in vitro suggest that the placenta adapts to a changing oxygen environment by maintaining its core functions anchorage, EVT migration, hormone production, and nutrient transfer but that it adjusts the rate of each process to meet fetal requirements at specific developmental stages.

Placental hypoxia, prolonged beyond the first trimester, is now recognized as a probable cause of pregnancy pathology $(12,13)$. Thus, for example, preeclampsia is associated with failed transformation of maternal spiral arteries by EVT (18). TGF- $\beta 3$ overexpression has been reported in preeclamptic placenta (14). Some authors have linked preeclampsia to a failure of EVT migration, and Caniggia et al. (14) suggest

\section{Cytotrophoblasts transform the arterial walls, allowing the blood supply to increase with fetal demands.}

that elevated TGF- $\beta 3$ and a consequent inhibition of cell differentiation may be responsible for this failure. However, interstitially migrating EVT are abundant in the preeclamptic placental bed (18). Hence, the inability of these cells to enter and transform the arteries remains unexplained.

The TGF $\beta$ family is controlled by proteases, binding proteins, and receptors, and more information is needed about the availability and activity of these molecules at the maternal-fetal interface. The explant model of EVT differentiation represents a significant technical advance. Assays of this kind that reflect, as faithfully as possible, the gravid uterine environment will play a vital role in elucidating developmental mechanisms and should lead to earlier and more effective treatments for pregnancy pathology. 
1. Jaffe, R., Jauniaux, E., and Hustin, J. 1997. Maternal circulation in the first-trimester human placenta: myth or reality? Am. J. Obstet. Gynecol. 176:695-705

2. Burton, G.J., Jauniaux, E., and Watson, A.L. 1999 Maternal arterial connections to the placental intervillous space during the first trimester of human pregnancy: the Boyd collection revisited. Am. J. Obstet. Gynecol. 181:718-724.

3. Rodesch, F., Simon, P., Donner, C., and Jauniaux, E. 1992. Oxygen measurements in endometria and trophoblastic tissues during early pregnancy. Obstet. Gynecol. 80:283-285.

4. Watson, A.L., Skepper, J.N., Jauniaux, E., and Burton G.J. 1998. Susceptibility of human placenta syncytiotrophoblastic mitochondria to oxygenmediated damage in relation to gestational age. $J$. Clin. Endocrinol. Metab. 83:1697-1705.

5. Caniggia, I., et al. 2000. Hypoxia-inducible factor1 mediates the biological effects of oxygen on human trophoblast differentiation through TGFß3. J. Clin. Invest. 105:577-587 (2000).

6. Aplin, J.D., Haigh, T., Vicovac, L.J., Church, H.J., and Jones, C.J.P. 1998. Anchorage in the developing placenta: an overlooked determinant of pregnancy outcome? Hum. Fertil. 1:75-79.

7. Pijnenborg, R., Dixon, G., Robertson, W.B., and Brosens, I. 1980. Trophoblastic invasion of human decidua from 8 to 18 weeks of pregnancy. Placenta. 1:3-19.

8. Vicovac, L.J., and Aplin, J.D. 1996. Epithelialmesenchymal transition during trophoblast dif ferentiation. Acta Anat. (Basel). 156:202-216.

9. Aplin, J.D., Haigh, T., Jones, C.J.P., Church, H.J., and Vicovac, L.J. 1999. Development of cytotrophoblast columns from explanted first trimester placental villi: role of fibronectin and integrin $\alpha 5 \beta 1$. Biol. Reprod. 60:828-838.

10. Genbacev, O., Zhou, Y., Ludlow, J.W., and Fisher, S.J. 1997. Regulation of human placental development by oxygen tension. Science. 277:1689-1672

11. Genbacev, O., Joslin, R., Damsky, C.H., Polliotti, B., and Fisher, S.J. 1997. Hypoxia alters early gestation human cytotrophoblast differentiation/invasion in vitro and models the placental defects that occur in pre-eclampsia. J. Clin. Invest. 97:540-550.

12. Fox, H. 1964. The villous trophoblast as an index of placental ischaemia. J. Obstet. Gynaecol. Brit. Comm. 71:885-893.
13. Kingdom, J.C.P., and Kaufmann, P. 1997. Oxygen and placental villous development: origins of fetal hypoxia. Placenta. 18:613-621.

14. Caniggia, I., Grisaru-Gravnosky, S., Kuliszewski, M., Post, M., and Lye, S.J. 1999. Inhibition of TGF $\beta 3$ restores the invasive capacity of extravillous trophoblasts in pre-eclamptic pregnancies. J. Clin. Invest. 103:1641-1650.

15. Irving, J.A., and Lala, P.K. 1995. Functional roles of cell surface integrins on human trophoblast cell migration: regulation by TGF $\beta$, IGF-II and IGFBP-1. Exp. Cell Res. 217:419-427.

16. Kaufmann, P., and Castellucci, M. 1997. Extravillous trophoblast in the human placenta. Trophoblast Res. 10:21-65.

17. Graham, C.H., Lysiak, J.J., McCrae, K.R., and Lala, P.K. 1992. Localisation of TGF $\beta$ at the human fetal-maternal interface: role in trophoblast growth and differentiation. Biol. Reprod. 46:561-572.

18. Pijnenborg, R., Vercruysse, L., Verbist, L., and Van Assche, F.A. 1998. Interaction of interstitial trophoblast with placental bed capillaries and venules of normotensive and pre-eclamptic pregnancies. Placenta. 19:569-575. 